\title{
Distinct severity of phenotype in Hajdu- Cheney syndrome: a case report and literature review
}

\author{
Chunhua Zeng', Yunting Lin', Zhikun Lu', Zhen Chen², Xiaoling Jiang ${ }^{1}$, Xiaojian Mao', Zongcai Liu', Xinshuo Lu',
} Kangdi Zhang ${ }^{1}$, Qiaoli Yu ${ }^{3}$, Xiaoya Wang ${ }^{4}$, Yonglan Huang ${ }^{1}$ and Li Liu ${ }^{1 *}$ (D)

\begin{abstract}
Background: Hajdu-Cheney syndrome (HCS) is a rare inherited skeletal disorder caused by pathogenic mutations in exon 34 of NOTCH2. Its highly variable phenotypes make early diagnosis challenging. In this paper, we report a case of early-onset HCS with severe phenotypic manifestations but delayed diagnosis.

Case presentation: The patient was born to non-consanguineous, healthy parents of Chinese origin. She presented facial anomalies, micrognathia and skull malformations at birth, and was found hearing impairment, congenital heart disease and developmental delay during her first year of life. Her first visit to our center was at 1 year of age due to cardiovascular repair surgery for patent ductus arteriosus (PDA) and ventricular septal defect (VSD). Skull X-ray showed wormian bones. She returned at 7 years old after she developed progressive skeletal anomalies with fractures. She presented with multiple wormian bones, acro-osteolysis, severe osteoporosis, bowed fibulae and a renal cyst. Positive genetic test of a de novo heterozygous frameshift mutation in exon 34 of NOTCH2 (c.6426dupT) supported the clinical diagnosis of HCS.

Conclusion: This is the second reported HCS case caused by the mutation c.6426dupT in NOTCH2, but presenting much earlier and severer clinical expression. Physicians should be aware of variable phenotypes so that early diagnosis and management may be achieved.
\end{abstract}

Keywords: NOTCH2, Hajdu-Cheney syndrome, Osteoporosis, Acro-osteolysis

\section{Background}

Hajdu-Cheney syndrome (HCS; OMIM 102500) is an extremely rare and heterogeneous disease that can be characterized by craniofacial anomalies, acro-osteolysis, progressive osteoporosis with fractures, congenital heart defects, hearing impairment, polycystic kidneys, short stature and developmental delay [1-3]. HCS exhibits autosomal dominant inheritance, but there have been several sporadic cases previously reported. Truncating

\footnotetext{
* Correspondence: liliuchina@qq.com

'Department of Genetics and Endocrinology, Guangzhou Women and Children's Medical Center, Guangzhou Medical University, 9 Jinsui Rd, Guangzhou 510623, China

Full list of author information is available at the end of the article
}

mutation in Notch homolog protein 2 gene (NOTCH2) was reported as the main cause of HCS [4-6]. The NOTCH2 gene, located on 1p12-p11 (NM_024408.3), encodes a transmembrane protein critical in skeletal development and bone remodeling by acting on the cells of osteoclast and osteoblast lineage [7]. The NOTCH2 mutation is a gain of function, as it results in a longer half-life for NOTCH2 protein [8, 9]. The enhanced $\mathrm{NOTCH} 2$ activity promotes osteoclastogenesis and inhibits osteogenesis.

To date, fewer than 100 HCS cases have been described in medical literature, with only few cases regarding the Chinese population $[10,11]$. The clinical manifestation in

(C) The Author(s). 2020 Open Access This article is licensed under a Creative Commons Attribution 4.0 International License, which permits use, sharing, adaptation, distribution and reproduction in any medium or format, as long as you give appropriate credit to the original author(s) and the source, provide a link to the Creative Commons licence, and indicate if changes were made. The images or other third party material in this article are included in the article's Creative Commons licence, unless indicated otherwise in a credit line to the material. If material is not included in the article's Creative Commons licence and your intended use is not permitted by statutory regulation or exceeds the permitted use, you will need to obtain permission directly from the copyright holder. To view a copy of this licence, visit http://creativecommons.org/licenses/by/4.0/ The Creative Commons Public Domain Dedication waiver (http://creativecommons.org/publicdomain/zero/1.0/) applies to the data made available in this article, unless otherwise stated in a credit line to the data. 
HCS is highly variable, which makes early diagnosis challenging, resulting in delayed diagnosis in many cases [12, 13]. Here, we report a Chinese girl with HCS who exhibited significant phenotypes during her first year of life, but was only diagnosed at the age of 7 years after developing severe osteoporosis with fractures.

\section{Case presentation}

\section{Patient's characteristics}

The patient, a seven-year-old Chinese girl, was the first child born to healthy non-consanguineous parents. Her birth weight was $3200 \mathrm{~g}$. She was found facial anomalies including small mouth, flat nasal base, long philtrum and micrognathia at the age of few months. No positive family history was noted.

\section{Clinical and radiological findings}

At one year old, the patient was found to have a ventricular septal defect (VSD), patent ductus arteriosus (PDA), pulmonary hypertension and developmental delay after experiencing several episodes of pneumonia. The patient also had an open anterior fontanelle $(0.5$ $\mathrm{cm} \times 1.0 \mathrm{~cm})$ and focal defects of the occipital bones. Radiographs showed normal arms and fingers (Fig. 2e). Computed Tomography (CT) Scan of the head revealed wormian cranial bones and patent cranial sutures (Fig. 2a). Magnetic resonance imaging (MRI) of the brain was interpreted as normal. At 1 year and 2 months, a successful repair surgery for congenital heart defects was done. Hearing impairment, progressive skeletal anomalies, gross motor and verbal delay and short stature were subsequently noticed by the parents. However, the patient did not undergo further examination until she was 5 years old, during which she presented developmental delay and facial dysmorphism. Her serum alkaline (ALP), calcium and phosphorus levels were all within normal range at the time (Table 1).

The patient came back to our clinic at the age of 7 years due to experiencing metatarsal fractures twice within the past 3 months. She presented with distinct facial dysmorphism, multiple skeletal anomalies, hearing impairment and mild delay of mental development (Table 2). Her physical examination was significant for short stature with a height of $110.8 \mathrm{~cm}(<3 \mathrm{rd}$ percentile) and weight of $15.5 \mathrm{~kg}$ ( $<3 \mathrm{rd}$ percentile), a small mouth, coarse and thick hair, wide and arched eyebrows, a flat and broad nasal base, a long philtrum and micrognathia (Fig. 1a and b). In addition, she showed occipital skull defects, dysmorphic sternum, dysmorphic hands and feet, short fingers, wide nails and joint hyperlaxity (Fig. 1c-e). Her teeth were misaligned and abnormally shaped with dental malocclusion. Blood tests showed normal liver and renal function. Serum calcium, phosphate and parathyroid hormone levels were all in normal range. Serum ALP had kept increasing and reached to $558 \mathrm{U} / \mathrm{L}$ by the time she was 7 years old, which was much higher than the upper limit of normal range (Table 1). Serum bone ALP (BALP) was also higher than the upper limit of normal range. Urine was not collected and tested for bone resorption. A hearing test revealed bilateral conductive hearing impairment with a threshold of $48 \mathrm{~dB}$ in the right ear and $55 \mathrm{~dB}$ in the left ear. Head CT exhibited multiple wormian bones in the skull (Fig. 2b). Radiographs detected misaligned and abnormally shaped teeth with dental malocclusion, acroosteolysis in distal phalanges of the fingers, wormian bones in the dysmorphic sternum, curved fibulae and a shortened left toe (Fig. 2c, d, f-h). Abdominal ultrasonography revealed a $5 \mathrm{~mm} \times 4 \mathrm{~mm}$ renal cyst. Ultrasound bone sonometer detected low bone mineral density (BMD) in the long bones.

\section{Genetic analysis}

After obtaining informed consent, genomic DNA was extracted from peripheral leukocytes of the patient and her parents. Next-generation sequencing (NGS) identified a duplication at position 6426 of the $\mathrm{NOTCH} 2$ gene (exon 34) (NM-024408, c. 6426dupT) (Fig. 3). Sanger sequencing subsequently confirmed the mutation as de novo in the proband but not in her parents. The truncating mutation of c.6426dupT was reported as a pathogenic variant causing a frameshift change (p.E2143X).

\section{Discussion and conclusion}

HCS is a rare autosomal dominant disorder caused by a gain-of-function mutation in the gene $\mathrm{NOTCH} 2$. A total

Table 1 Osteologic characterization of the HCS patient during 6 year follow-up

\begin{tabular}{lllll}
\hline Parameter & 1 year old & 5 year old & 7year old & Normal range \\
\hline Serum ALP $(\mathrm{U} / \mathrm{l})$ & 112.0 & 313.0 & 558.0 & $118.0-390.0$ \\
Serum Calcium $(\mathrm{mmol} / \mathrm{L})$ & 2.2 & 2.3 & 2.4 & $2.2-2.7$ \\
Serum Phosphorus $(\mathrm{mmol} / \mathrm{L})$ & - & 1.2 & 1.7 & $1.3-1.9$ \\
Serum PTH (pmol/L) & - & - & 2.7 & $1.2-7.1$ \\
Serum BALP $(\mathrm{U} / \mathrm{l})$ & - & - & 240.0 & $0-200.0$ \\
Serum 25(OH) D (nmol/L) & - & - & 66.0 & $50.0-150.0$ \\
\hline
\end{tabular}

ALP alkaline phosphatase, BALP bone alkaline phosphatase, $P T H$ Parathyroid hormone, $25(\mathrm{OH}) D$ 25-hydroxyvitamin $D$ 


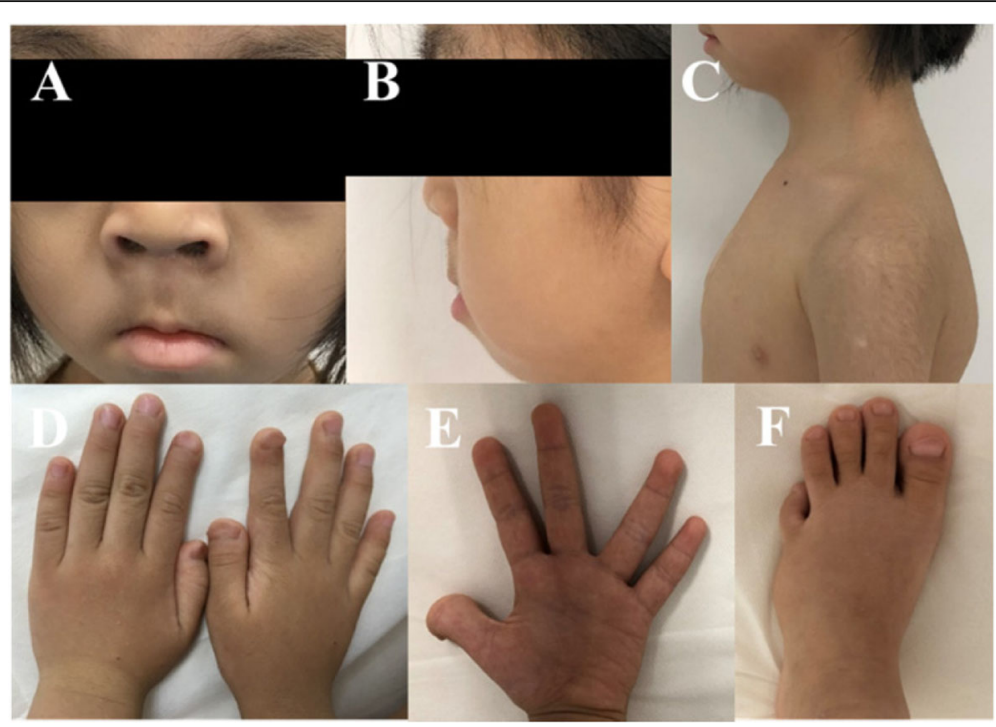

Fig. 1 Photographs of the patient at 7 years of age. $\mathbf{a}$ and $\mathbf{b}$ Facial anomalies include coarse and thick hair, wide and arched eyebrows, a flat and broad nasal base, a long philtrum and micrognathia; $\mathbf{c}$ Photographs show thick body hair and a dysmorphic sternum; $\mathbf{d}$ and $\mathbf{e})$ Shortened fingers and wide nails with pseudo-clubbing aspect; $\mathbf{f}$ Dysmorphic metatarsal bones and a shortened left toe

of 85 mutations have been reported, 55 of which are missense mutations. In a literature review of reported HCS cases, all NOTCH2 mutations are dispersed throughout the exon 34, and the most common mutation p.Q2208X was found in only 4 of the 36 families [14]. The clinical manifestations in reported HCS patients are highly variable, including facial dysmorphia, osteoporosis, acro-osteolysis, hearing impairment and dental implication [15]. Phenotypic variability resulted in diagnostic challenges and caused difficulty in predicting the clinical outcome from a specific genotype in HCS [15].

In this 7-year-old Chinese girl, we identified a de novo truncating mutation (c.6426dupT) in exon 34 of

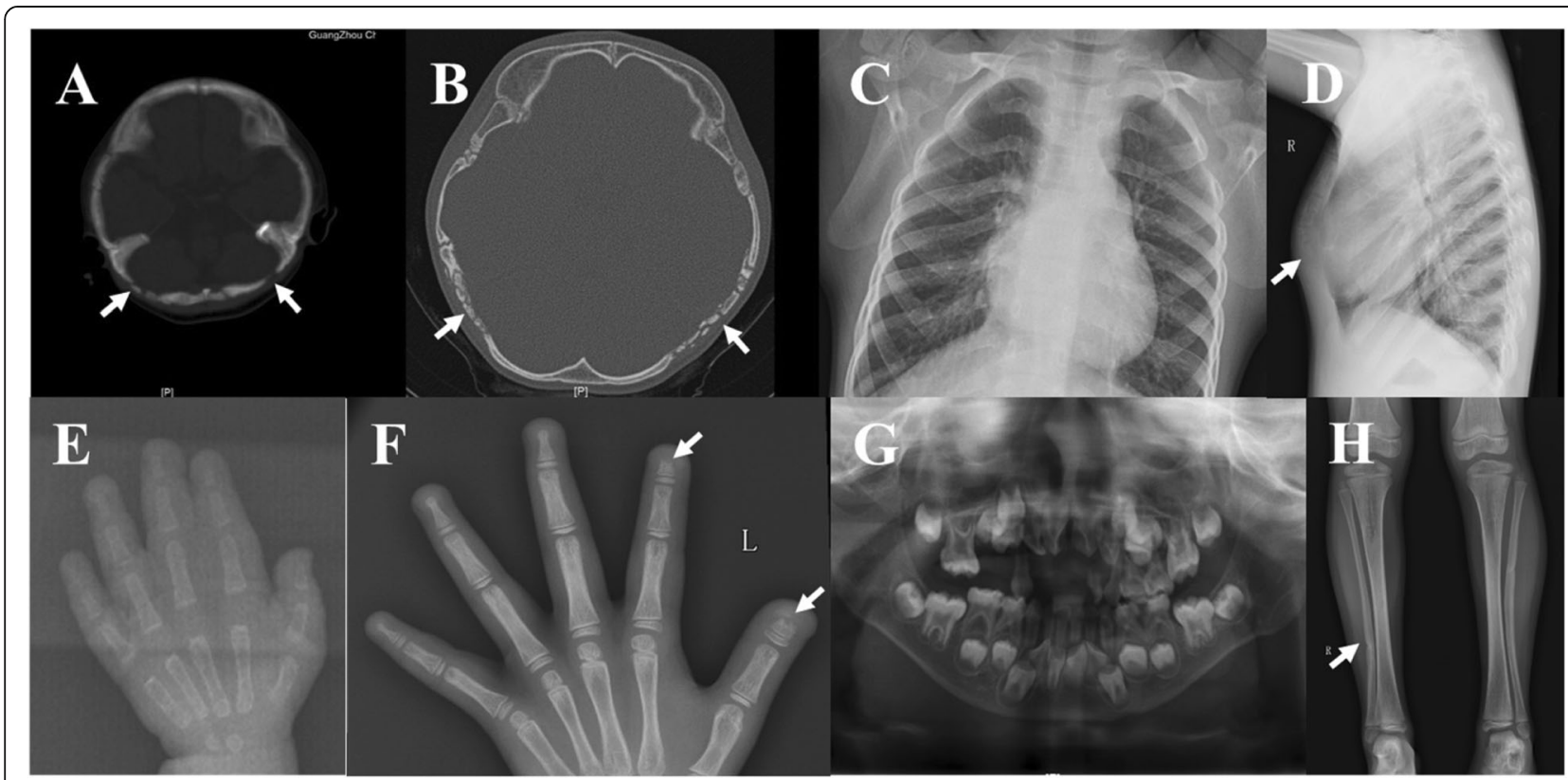

Fig. 2 Computed Tomography (CT) scan and radiographs. a and $\mathbf{b}$ Wormian bones (arrow) and patent cranial sutures at 1 year and 2 months of age and at 7 years of age, respectively; $\mathbf{c}$ and $\mathbf{d}$ Wormian bones and deformity of the sternum at 7 years of age (arrow); e and $\mathbf{f}$ Acro-osteolysis was not present at 1 year and 2 months of age but was present in the distal phalanges at 7 years of age (arrow); $\mathbf{g}$ Misaligned and abnormally shaped teeth with dental malocclusion at 7 years of age; $\mathbf{h}$ Radiographs exhibiting bowed fibulae at 7 years of age (arrow) 


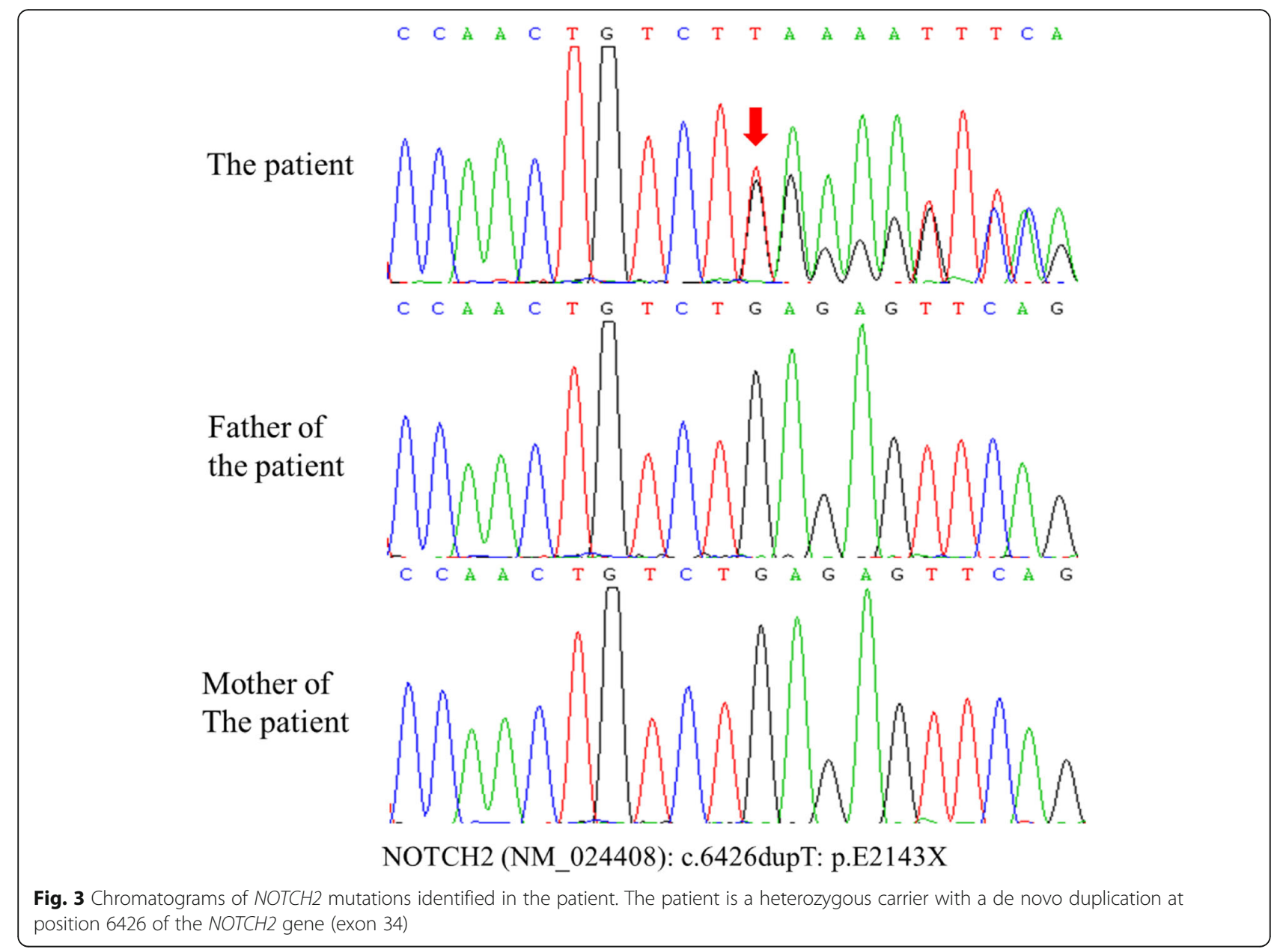

NOTCH2. The patient demonstrated the majority of clinical manifestations of HCS reported in previous studies. She presented with facial dysmorphia at birth, and as early as 1 year and 2 months old, she was found with cranial wormian bones, congenital heart disease and developmental delay. Chromosomal anomaly was suspected and then ruled out by karyotype analysis. After reparative surgery for PDA and VSD, the patient developed hearing impairment, periodontal disease and multiple skeletal anomalies in the following years. However, HCS was not diagnosed in this case until the patient had demonstrated severe osteoporosis with fractures, acroosteolysis, renal cyst and significant developmental delay at the age of 7 years.

Our report demonstrates that the mutation c.6426dupT in this patient manifested with early-onset phenotype and severe clinical expressions with progressive acro-osteolysis and osteoporosis, hearing impairment and renal cyst. A literature review indicated this is the second case with this mutation; the first was previously reported in a 19-yearold male with HCS [4]. To further investigate the phenotype of the c.6426dupT mutation, we compared our patient to the reported case in the literature. Table 2 summarizes clinical and radiological manifestations in the two patients with the mutation of c.6426dupT in NOTCH2. We found both patients to exhibit facial dysmorphia, periodontal disease, hearing deficit, short stature, congenital heart disease (PDA and VSD), acro-osteolysis, osteoporosis and wormian bones. Despite multiple systems being affected, the craniofacial and skeletal anomalies were shared characteristic manifestations in both patients. Comparatively, the patient in our study demonstrated more significant manifestations including micrognathia, bowing of the fibulae, metatarsal fracture and developmental delay, which was not described in the first reported case. Additionally, our patient presented most of her characteristic manifestations of HCS during her first year of life. These results suggest that HCS caused by the same causative mutation may present a broad range of clinical severity and distinct phenotypic expression, making both diagnosis and prognosis challenging.

HCS is associated with gain-of-function mutations. Recent studies have suggested that Notch2 inhibits osteoblast differentiation, and induces and enhances 
Table 2 Clinical features of two HCS patients carrying mutation c.6426dupT of NOTCH2

\begin{tabular}{|c|c|c|c|}
\hline \multirow{2}{*}{$\begin{array}{l}\text { The proband } \\
\text { Gender }\end{array}$} & \multirow{2}{*}{$\begin{array}{l}\text { The case in } \\
\text { the literature } \\
\text { Male }\end{array}$} & \multicolumn{2}{|c|}{$\begin{array}{l}\text { The patient in } \\
\text { current study }\end{array}$} \\
\hline & & Female & \\
\hline Age (yrs) & 19-year-old & 1-year-old & 7-year-old \\
\hline \multicolumn{4}{|l|}{ Craniofacial features } \\
\hline Facial dysmorphology & + & + & + \\
\hline Micrognathia & - & + & + \\
\hline Periodontal disease & + & - & + \\
\hline \multicolumn{4}{|l|}{ Cognitive/sensory function } \\
\hline Developmental delay & - & + & + \\
\hline Neurologic symptoms & + & + & + \\
\hline Hearing deficit & + & + & + \\
\hline \multicolumn{4}{|l|}{ General physical features } \\
\hline Short stature & + & + & + \\
\hline Congenital heart defect & PDA, VSD & PDA, VSD & repaired $\mathrm{CHD}$ \\
\hline Polycystic kidneys & - & - & + \\
\hline Joint hyperlaxity & + & + & + \\
\hline \multicolumn{4}{|l|}{ Radiographic abnormalities } \\
\hline Acroosteloysis & + & - & + \\
\hline Osteoporosis & + & - & + \\
\hline Wormian bones & + & + & + \\
\hline Bowing of the fibula & - & - & + \\
\hline Vertebral compression & - & - & - \\
\hline \multicolumn{4}{|l|}{ Additional features } \\
\hline Dysmorphic sternum & - & - & + \\
\hline Metatarsal fracture & - & - & + \\
\hline
\end{tabular}

$P D A$ patent ductus arteriosus, VSD ventricular septal defect, $C H D$ congenital heart disease

osteoclastogenesis [16-19]. A mouse model of HCS further supported that bone loss is secondary to increased osteoclastogenesis and bone resorption [16]. Another study indicated that HCS not only presents as increased osteoclastogenesis, but also displays activated osteoblast activity with high bone turnover [17]. Similarly, the patient in our study exhibits osteologic features with increased bone formation. After her first bone fracture, the patient was prescribed with calcium and Vitamin D, and then followed up at our clinic for 8 months. However, she was not given anti-resorptive treatment due to her age and the parents' concerns.

In conclusion, the findings support that the mutation c.6426dupT is pathogenic. Our study demonstrated variable degrees of expression and distinct severity of phenotype amongst HCS patients carrying the same NOTCH 2 mutation. The variability of phenotype indicates that there may be other modifier acting on the expression of truncating mutations in exon 34 of the gene
NOTCH2. Although the mechanism resulting in HCS is not fully understood, physicians should be aware of variable phenotypes so that early diagnosis and management can be achieved.

\section{Abbreviations}

CT: Computed tomography; HCS: Hajdu-Cheney syndrome; MRI: Magnetic resonance imaging; NOTCH2: Notch homolog protein 2 gene; PDA: Patent ductus arteriosus; VSD: Ventricular septal defect

\section{Acknowledgements}

The authors would like to thank the patient and her parents for their involvement in the present study. They would like to also thank Dr. Guoging Hou and Dr. Helmut Grasberger at the University of Michigan for their English editing. Lastly, they would like to thank Dr. Junyi Xie at the Guangzhou Women and Children's Medical Center for her kind help.

\section{Statement for CARE guidelines}

We adhere to CARE guidelines/methodology when writing this case report.

\section{Authors' contributions}

This work was carried out in collaboration between all authors. CHZ, LL, YLH and XYW designed the study; ZCL and XJM acquired the data; YTL, XLJ and ZKL performed the experiments. XSL, KDZ and $\mathrm{CHZ}$ analyzed the data; $\mathrm{CHZ}$, ZC and QLY wrote the manuscript; LL and YLH gave technical support and conceptual advice. All authors read and approved the final manuscript.

\section{Funding}

This work was supported by the Medical Scientific Research Foundation of Guangdong Province, China (A2018546) and Research Grants from Guangzhou Women and Children's Medical Center (5001-4001003). Funders were not involved in data analysis or interpretation.

\section{Availability of data and materials}

Not applicable. All data concerning the case are presented in the manuscript.

\section{Ethics approval and consent to participate}

The study was approved by the Medical Ethics Committee for Clinical Ethical Review, Guangzhou Women and Children's Medical Center ([2019] No.41301). A written informed consent was obtained for genetic testing from the parent of the patient.

\section{Consent for publication}

A written, signed informed consent to publish this case and any accompanying images was obtained from the parent of the patient.

\section{Competing interests}

The authors declare that they have no competing interests.

\section{Author details}

1Department of Genetics and Endocrinology, Guangzhou Women and Children's Medical Center, Guangzhou Medical University, 9 Jinsui Rd, Guangzhou 510623, China. ${ }^{2}$ Department of Radiology, Guangzhou Women and Children's Medical Center, Guangzhou Medical University, 9 Jinsui Rd, Guangzhou 510623, China. ${ }^{3}$ Department of Dentistry, Guangzhou Women and Children's Medical Center, Guangzhou Medical University, 9 Jinsui Rd, Guangzhou 510623, China. ${ }^{4}$ Department of Otolaryngology, Guangzhou Women and Children's Medical Center, Guangzhou Medical University, 9 Jinsui Rd, Guangzhou 510623, China.

Received: 8 October 2019 Accepted: 28 February 2020

Published online: 06 March 2020

\section{References}

1. Canalis E, Zanotti S. Hajdu-Cheney syndrome: a review. Orphanet J Rare Dis, 2014;9:200.

2. Cheney WD. ACRO-OSTEOLYSIS. Am J Roentgenol Radium Therapy, Nucl Med. 1965:94:595-607.

3. Hajdu N, Kauntze R. Cranio-skeletal dysplasia. Br J Radiol. 1948;21:42-8. 
4. Isidor B, Lindenbaum P, Pichon O, Bezieau S, Dina C, Jacquemont S, et al. Truncating mutations in the last exon of NOTCH2 cause a rare skeletal disorder with osteoporosis. Nat Genet. 2011;43:306-8.

5. Majewski J, Schwartzentruber JA, Caqueret A, Patry L, Marcadier J, Fryns JP, et al. Mutations in NOTCH2 in families with Hajdu-Cheney syndrome. Hum Mutat. 2011;32:1114-7.

6. Simpson MA, Irving MD, Asilmaz E, Gray MJ, Dafou D, Elmslie FV, et al. Mutations in NOTCH2 cause Hajdu-Cheney syndrome, a disorder of severe and progressive bone loss. Nat Genet. 2011;43:303-5.

7. Canalis E, Schilling L, Yee SP, Lee SK, Zanotti S. Hajdu Cheney mouse mutants exhibit osteopenia, increased Osteoclastogenesis, and bone Resorption. J Biol Chem. 2016;291:1538-51.

8. Yu J, Canalis E. The Hajdu Cheney mutation sensitizes mice to the osteolytic actions of tumor necrosis factor alpha. J Biol Chem. 2019;294:14203-14.

9. Zhao W, Petit E, Gafni Rl, Collins MT, Robey PG, Seton M, et al. Mutations in NOTCH2 in patients with Hajdu-Cheney syndrome. Osteoporos Int. 2013;24: 2275-81.

10. Gu JM, Hu YQ, Zhang H, Wang C, Hu WW, Yue H, et al. A mutation in NOTCH2 gene in a Chinese patient with Hajdu-Cheney syndrome. Joint Bone Spine. 2013;80:548-9.

11. Gong RL, Wu J, Chen TX. A Novel Mutation of Notch homolog protein 2 gene in a Chinese Family with Hajdu-Cheney Syndrome. Chin Med J. 2017; 130:2883-4.

12. Han MS, Ko JM, Cho TJ, Park WY, Cheong HI. A novel NOTCH2 mutation identified in a Korean family with Hajdu-Cheney syndrome showing phenotypic diversity. Ann Clin Lab Sci. 2015:45:110-4.

13. Regev M, Pode-Shakked B, Jacobson JM, Raas-Rothschild A, Goldstein DB, Anikster Y. Phenotype variability in Hajdu-Cheney syndrome. Eur J Med Genet. 2019;62:35-8.

14. Narumi Y, Min BJ, Shimizu K, Kazukawa I, Sameshima K, Nakamura K, et al. Clinical consequences in truncating mutations in exon 34 of $\mathrm{NOTCH}$ : report of six patients with Hajdu-Cheney syndrome and a patient with serpentine fibula polycystic kidney syndrome. Am J Med Genet A. 2013; 161a:518-26.

15. Lee JW, Kim YJ, Kang J, Shin TJ, Hyun HK, Kim YJ, et al. Dental implications in Hajdu-Cheney syndrome: a novel case report and review of the literature. Oral Dis. 2018:24:1037-41.

16. Canalis E. Clinical and experimental aspects of notch receptor signaling: Hajdu-Cheney syndrome and related disorders. Metabolism. 2018:80:48-56.

17. Vollersen N, Hermans-Borgmeyer I, Cornils K, Fehse B, Rolvien T, Triviai I, et al. High bone turnover in mice carrying a pathogenic Notch2 mutation causing Hajdu-Cheney syndrome. J Bone Miner Res. 2018;33:70-83.

18. Hilton MJ, Tu X, Wu X, Bai S, Zhao H, Kobayashi T, et al. Notch signaling maintains bone marrow mesenchymal progenitors by suppressing osteoblast differentiation. Nat Med. 2008;14(3):306-14.

19. Zanotti S, Smerdel-Ramoya A, Stadmeyer L, Durant D, Radtke F, Canalis E. Notch inhibits osteoblast differentiation and causes osteopenia. Endocrinology. 2008:149(8):3890-9.

\section{Publisher's Note}

Springer Nature remains neutral with regard to jurisdictional claims in published maps and institutional affiliations.

Ready to submit your research? Choose BMC and benefit from:

- fast, convenient online submission

- thorough peer review by experienced researchers in your field

- rapid publication on acceptance

- support for research data, including large and complex data types

- gold Open Access which fosters wider collaboration and increased citations

- maximum visibility for your research: over $100 \mathrm{M}$ website views per year

At $\mathrm{BMC}$, research is always in progress.

Learn more biomedcentral.com/submissions 